\title{
SCIDiC
}

\author{
International Journal of Dentistry and Oral Science (IJDOS) \\ ISSN: 2377-8075
}

\section{Relation between Dental Student's Emotional Intelligence (EI) and their Perceived Stress Level in Chennai- A Cross Sectional Study}

Research Article

Indumathy Pandiyan ${ }^{1}$, Leelavathi.L ${ }^{2,4^{*}}$, Pradeep Kumar Rathinavelu ${ }^{3}$

${ }^{1}$ Post Graduate, Department of Public Health Dentistry, Saveetha Dental College \& Hospitals, Saveetha Institute of Medical and Technical Sciences, Saveetha University, Vellapanchavi, Chennai-600077, Tamilnadu, India.

${ }^{2}$ Senior Lecturer, Department of Public Health Dentistry, Saveetha Dental College \& Hospitals, Saveetha Institute of Medical and Technical Sciences, Saveetha University, Vellapanchavi, Chennai-600077, Tamilnadu, India.

${ }^{3}$ Professor and Head of the Department, Department of Public Health Dentistry, Saveetha Dental College \& Hospitals, Saveetha Institute of Medical and Technical Sciences, Saveetha University, Vellapanchavi, Chennai-600077, Tamilnadu, India.

${ }^{4}$ Professor, Department of Public Health Dentistry, Saveetha Dental College \& Hospitals, Saveetha Institute of Medical and Technical Sciences, Saveetha University, Vellapanchavi, Chennai-600077, Tamilnadu, India.

\section{Abstract}

Context: Emotional intelligence (EI) is a social form of intelligence that enables people to recognize their own and others' emotions and to make appropriate choices for thinking and action. Dental students can experience high levels of stress. Emotional intelligence can moderate stress and increase wellbeing. The aim of the study is to determine the relation between dental student's emotional intelligence and their perceived stress level.

Aims: The aim of the study is to determine the relation between dental student's emotional intelligence and their perceived stress level.

Methods and Material: A cross sectional questionnaire study was conducted among 177 dental students in Chennai in which Emotional Intelligence was measured using the Schutte et al Emotional Intelligence scale and stress level was measured using the Perceived Stress Scale (PSS). The questionnaire was filled by the surveyed subjects

Statistical analysis used: Descriptive statistics was done to represent the demographic characteristics of the participants. Pearson's correlation was used to explore the relationship between EI and PS. Pearson's correlation, independent samples t-tests and analysis of variance were conducted to explore the relationship between demographic variables and EI and PS. Analysis of variance was used to compare four domains of EI. Statistical significance was set at $\mathrm{P}=0.05$.

Results: Most of the study participants were females which constitutes $83.1 \%$ and males $16.9 \%$. There existed a negative correlation between EI and PS ( $\mathrm{r}=-0.45, \mathrm{p}=0.27)$, indicating that as $\mathrm{EI}$ increased, PS decreased. A significant negative correlation was found between EI and PS among the students. No difference was found in EI across the domains.

Conclusions: A significant negative correlation was found between EI and PS among the students. No difference was found in EI across the domains.

Keywords: Dental Students; Emotional Intelligence; Personal Skills; Student's Attitude; Stress Level.

\section{Introduction}

Emotional intelligence (EI) has been defined as "the ability to monitor one's own and other people's emotions, to discriminate between different emotions and label them appropriately, and to use emotional information to guide thinking and behaviour [1]. Emotional intelligence (EI) is a social type of knowledge that em- powers individuals to perceive their own and others' emotions and to settle on suitable decisions for speculation and activity [2]. Emotional intelligence brings together the fields of emotions and intelligence by viewing emotions as useful sources of information that help one to make sense of and navigate the social environment [3]. Emotional intelligence has the following common components or factors: perceiving, understanding, using, and

*Corresponding Author

Dr. Leelavathi.L,

Senior Lecturer, Department of Public Health Dentistry, Saveetha Dental College \& Hospitals, Saveetha Institute of Medical and Technical Sciences, Saveetha University, Vellapanchavi, Chennai-600077, Tamilnadu, India.

Tel: 8220870849

E-mail: karleela81@gmail.com

Received: January 13, 2021

Accepted: February 08, 2021

Published: February 18, 202

Citation: Indumathy Pandiyan, Leelavathi.L, Pradeep Kumar Rathinavelu. Relation between Dental Student's Emotional Intelligence (EI) and their Perceived Stress Level in Chennai- A Cross Sectional Study. Int J Dentistry Oral Sci. 2021;8(2):1647-1650. doi: http://dx.doi.org/10.19070/2377-8075-21000327

Copyright: Leelavathi. $\mathbf{L}^{\circ}$ 2021. This is an open-access article distributed under the terms of the Creative Commons Attribution License, which permits unrestricted use, distribution and reproduction in any medium, provided the original author and source are credited. 
managing emotions. Indeed, one's EI quotient has been found to account for $80 \%$ of the factors of success [4]. EI is increasingly considered to have a potential role in medicine, nursing, and other health care disciplines, supporting both personal mental health and professional practice [5]. Stress can be defined as "a condition or feeling experienced when a person perceives that the demands placed on them exceeds the resources the individual has available" [6]. Medical students may experience stress when their curricular demands exceed their resources to deal with them [7]. Psychological stress occurs when a person appraises a situation as exceeding their resources to cope and endangering their wellbeing [8].

The stress response ('fight', 'flight', 'freeze') is a mechanism adapted for dealing with short-term physical emergencies [9]. For such short-term emergencies the stress response is vital, but in the face of chronic stress, the constant demand to the body system is considered to be detrimental to health. While the detrimental effects of stress may be significant, recent research has shown that stress can also have a positive effect on physiological functioning [11]. More specifically, by positively reappraising stress as a tool to aid performance, participants in one study demonstrated a more adaptive physiological response to stress; as measured by greater cardiac output and less vasoconstriction, compared with participants assigned in other conditions $[10,11]$.

Dental education is one of the most challenging, demanding, and stressful fields of study, since dental students are expected to acquire diverse academic and clinical competencies and interpersonal skills [12]. For dental students (DS), the dental school curriculum and environment is known to be highly demanding and a stressful learning experience [13]. The primary aim of the study was to investigate the relationship between EI behaviours and PS among Dental students.

\section{Materials and Methods}

\section{Study Design and Area}

The present cross-sectional study was conducted among various dental college students in Chennai from August 2019 to February 2020 .

\section{Study Population}

A total of 177 subjects who were pursuing Internship from four dental institutions in Chennai were recruited using a cluster random sampling method. Participation was voluntary. Students took about 15 minutes to complete the questionnaire. A pilot study was conducted and the students were invited to participate in the study to assess the feasibility of the study population.

\section{Inclusion criteria}

Interns of dental colleges who were willing to participate in the study was included.

\section{Exclusion criteria}

Interns those who were not willing to participate in the study were excluded.

\section{Approval and informed consent}

Ethical clearance was obtained from the Institutional Review Board (IRB). Informed consent was obtained from the participants before they started filling the questionnaire.

Questionnaire: 1) The questionnaire was divided into three parts in which the first part includes their Demographic data of the students such as Name, age, year of the study, the second part includes the questionnaire of emotional intelligence and third part included the questionnaire of perceived stress level. 2) To assess the Emotional Intelligence of the students a pretested Schutte Self-Report Emotional Intelligence Test was used [14]. It is a 33 item validated self-reported measure of emotional intelligence developed by Schutte, et al. based on the EI model proposed by Salovey and Mayer. Participants' response to each question is based on a 5-point Likert scale ranging from strongly disagrees to strongly agree. For EI analysis, the score for each domain was obtained by adding the scores for that specific domain. The total score was the sum of all four domain scores. The total score ranges from 33 to 165 . Scores of less than 120 were considered low EI and $\geq 120$ as high EI. A score of $\geq 20$ in each domain was considered good EI; $16-19$ average EI; and $\leq 15$ poor EI. The scale comprises four subscales that consist of: a) perception of emotion, b) managing one's own emotions, c) managing others' emotions, and d) utilisation of emotions. 3) To assess the stress level of the students Cohen's Perceived stress level scale with 10 item questionnaire was used. Responses are scored using a fivepoint Likert scale, ranging from ' $0=$ Never' to ' $4=$ Very Often.' Higher scores indicate higher levels of PS. The PSS-10 has sound internal consistency reliability, with Cronbach's $\alpha=0.78$ [15].

\section{Results}

The sample consists of 177 Interns. Figure 1 shows the gender distribution of the study participants. Most of the participants were Females $(83.1 \%)$ when compared to males $(16.9 \%)$.

Emotional Intelligence, Perceived Stress:Statistically significant negative correlations were found between total EI and PS for the study participants $(\mathrm{r}=-0.45, \mathrm{p}=0.27)$, indicating that as EI increased, PS decreased. The mean (SD) for the total EI, PS was 123.95 (12.4) and 20.73(5.8) respectively.

EI between the domain effects: $\mathrm{P}=0.00$ (significant)

Schutte Self-Report EI normative mean (SD): 123.95 (12.4)

PS normative means (SD): 20.73 (5.8)

Difference in EI between the domains: Using ANOVA, there was statistically significant differences in EI score between the domains. Domain 1: Perception of Emotion 36.24 (4.48); Domain 2: Managing own Emotion 34.03 (4.51); Domain 3: Managing others Emotion 30.33 (3.50); Domain 4: utilization of emotion 23.37 (3.31). It was observed from the results that the mean score was highest among the domain 1: Perception of emotion category.

Independent sample t-tests were conducted to assess the relationship between gender and PS (Table 2). The mean and (SD) were: male 20.07 (5.02) vs. female 20.86 (6.06), $\mathrm{p}=0.14$. There was no statistically significant difference in PS scores between males and females for the study participants. From the inference it's clear 
Figure 1. Shows the gender distribution of study participants.

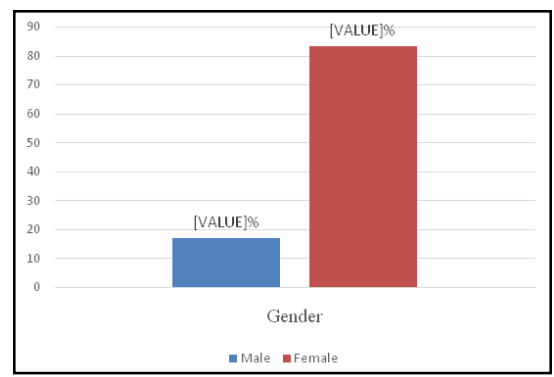

Table 1. Shows the distribution of EI scores across the four domains.

\begin{tabular}{|c|c|}
\hline Emotional Intelligence(Domain) & EI scores -Mean (SD) \\
\hline Domain 1 (Perception of Emotion) & $36.24(4.48)$ \\
\hline Domain 2 (Managing own Emotion) & $34.03(4.51)$ \\
\hline Domain 3 (Managing others Emotion) & $30.33(3.50)$ \\
\hline Domain 4 (utilization of emotion) & $23.37(3.31)$ \\
\hline
\end{tabular}

Table 2. Shows the independent sample t-tests to assess the relationship between gender and PS.

\begin{tabular}{|c|c|}
\hline & Perceived Stress \\
\hline Male mean (SD) & $20.07(5.02)$ \\
\hline Female mean (SD) & $20.86(6.06)$ \\
\hline P Value & 0.14 \\
\hline
\end{tabular}

that the emotional intelligence was higher among females with increasing stress level.

\section{Discussion}

Aptitudes for a service and caring orientation may be reflected by one's emotional intelligence [16].

In this study the EI and PS of dental students were measured and the relationship between demographic variables and EI and PS was tested; differences in EI and PS scores between the students; and differences in EI and PS in the student sample compared to normative means. In line with the findings of McKinley, Weng et al, Faye et al. and Zeidner et al.[17-20] the students become older, they become more emotionally intelligent $(r=0.187, \mathrm{p}=0.008)$.

The Assessing Emotions Scale was first developed and validated as an English language scale and the majority of studies using the scale have focused on participants from English speaking countries. Hebrew and Polish show that these other language versions of the scale result in hypothesised findings, such as that Assessing Emotions Scale scores are related to better supervisor-rated work performance [21].

Faye et al, who reported that residents who worked more than 50 hours per week were less emotionally intelligent [19]. Emotional intelligence is negatively associated with deviant behaviour in male adolescents [22]. Lopes et al, however, examined the relationship between individuals' emotional intelligence and reports of their attributes by their peers [23].

Birks et al note that, although EI moderates stress, this effect may be more potent at lower stress levels than when acute stressors are present. He used the PSS-10 and Schutte Emotional Intelligence scale, both EI and stress scores changed across two administrations and the degree of change was significantly correlated. Students whose stress scores increased between the two time points were likely to have scored lower on the EI measure and vice versa. This result is consistent with acute stress causing a drop in EI, however making such a claim is beyond the scope of a correlational design [5]. No significant correlation was found on age and PS for dental students.

For the study population, there was no significant relationship between age and EI. However, the relationship between EI \& PS was negatively correlated. Pau et al also found a weak, nonsignificant correlation between those measures in Australian dentistry students, while correlations were stronger for students from other countries. The current findings suggest different factors may be influencing Australian dentistry students than those studying nursing and pharmacy; however the reasons for this are not clear and need further investigation [24].

No difference in overall EI scores between female and male students was found. Female pharmacy students were significantly more stressed than male counterparts (moderate effect size). There was no significant relationship between gender and PS for nursing or dentistry students, however, mean PS scores were higher for females in all disciplines [5, 25, 26]. Polychronopoulos and Divaris (2010) reported that female dentistry students scored higher than males on stress scales for workload, performance pressure, and self-efficacy beliefs [27].

\section{Study Limitations and Recommendations}

This study is limited to a single survey at one-time point with a group of dental students and may not be generalizable to students in other contexts. It is possible that owing to the smaller sample 
size, some analyses were underpowered. Further work, including qualitative research, is needed to explain the mechanisms by which EI and stress are linked in these groups. In particular, the nature of the relationship between EI and acute stress requires further examination on causal factors. EI has a protective effect against stress and can be increased via targeted educational interventions. There is a clear need for pre-registration healthcare curricula to include educational components focused on strengthening EI. The need for university student counselling services and stress management support is also indicated. Future research is needed to investigate EI, stress, and wellbeing outcomes for students with/out an evidence-based intervention to increase EI.

\section{Conclusion}

Within the limits of the study, it was concluded that the study participants have good emotional intelligence. Highest EI score was observed in perception of emotion domain and the least score in utilisation of emotion. The mean score was highest among female (20.86) than male (20.07). Emotional intelligence and Perceived stress was negatively correlated among the study participants.

\section{References}

[1]. Goldstein S, Princiotta D, Naglieri JA. Handbook of Intelligence: Evolutionary Theory, Historical Perspective, and Current Concepts [Internet]. Springer; 2014. $498 \mathrm{p}$.

[2]. Salovey P, Sluyter DJ. Emotional Development and Emotional Intelligence: Educational Implications [Internet]. Basic Books (AZ); 1997. 288 p.

[3]. Dugan JW, Weatherly RA, Girod DA, Barber CE, Tsue TT. A longitudinal study of emotional intelligence training for otolaryngology residents and faculty. JAMA Otolaryngol Head Neck Surg [Internet]. 2014 Aug; 140(8):7206. Pubmed PMID: 25011036.

[4]. Mayer JD, Salovey P. The intelligence of emotional intelligence [Internet]. Vol. 17, Intelligence. 1993. p. 433-42.

[5]. Birks Y, McKendree J, Watt I. Emotional intelligence and perceived stress in healthcare students: a multi-institutional, multi-professional survey. BMC Med Educ. 2009 Sep 17;9:61. Pubmed PMID: 19761603.

[6]. The American Institute of Stress Seventh International Montreux Congress on Stress [Internet]. Vol. 11, Stress Medicine. 1995. p. 69-69.

[7]. Moffat KJ, McConnachie A, Ross S, Morrison JM. First year medical student stress and coping in a problem-based learning medical curriculum. Medical education. 2004 May;38(5):482-91.

[8]. Folkman S, Lazarus RS, Dunkel-Schetter C, DeLongis A, Gruen RJ. Dynamics of a stressful encounter: cognitive appraisal, coping, and encounter outcomes. J Pers Soc Psychol [Internet]. 1986 May;50(5):992-1003. Pubmed PMID:3712234.

[9]. Sapolsky RM. Why Zebras Don't Get Ulcers: The Acclaimed Guide to Stress, Stress-Related Diseases, and Coping - Now Revised and Updated [Internet].
Holt Paperbacks; 2004.560 p.

[10]. Jamieson JP, Mendes WB, Nock MK. Improving Acute Stress Responses [Internet]. Vol. 22, Current Directions in Psychological Science. 2013. p. 51-6.

[11]. Jamieson JP, Nock MK, Mendes WB. Mind over matter: reappraising arousal improves cardiovascular and cognitive responses to stress. J Exp Psychol Gen [Internet]. 2012 Aug;141(3):417-22. Pubmed PMID: 21942377.

[12]. Birks YF, Watt IS. Emotional intelligence and patient-centred care. J R Soc Med [Internet]. 2007 Aug;100(8):368-74. Pubmed PMID: 17682030.

[13]. Al-Samadani KH, Al-Dharrab A. The Perception of Stress among Clinical Dental Students [Internet]. Vol. 4, World Journal of Dentistry. 2013. p. 24-8

[14]. Schutte NS, Malouff JM, Hall LE, Haggerty DJ, Cooper JT, Golden CJ, Dornheim L. Development and validation of a measure of emotional intelligence. Personality and individual differences. 1998 Aug 1;25(2):167-77.

[15]. Cohen J. Statistical power analysis for the behavioral sciences. Academic press; 2013 Sep 3.

[16]. Romanelli F, Cain J, Smith KM. Emotional intelligence as a predictor of academic and/or professional success. American journal of pharmaceutical education. 2006 Jun 15;70(3).

[17]. McKinley SK, Petrusa ER, Fiedeldey-Van Dijk C, Mullen JT, Smink DS, Scott-Vernaglia SE, Kent TS, Black-Schaffer WS, Phitayakorn R. A multiinstitutional study of the emotional intelligence of resident physicians. The American Journal of Surgery. 2015 Jan 1;209(1):26-33.

[18]. Weng HC, Chen HC, Chen HJ, Lu K, Hung SY. Doctors' emotional intelligence and the patient-doctor relationship. Medical education. 2008 Jul;42(7):703-11.

[19]. Faye A, Kalra G, Swamy R, Shukla A, Subramanyam A, Kamath R. Study of emotional intelligence and empathy in medical postgraduates. Indian J Psychiatry [Internet]. 2011 Apr;53(2):140-4.

[20]. Zeidner M, Hadar D, Matthews G, Roberts RD. Personal factors related to compassion fatigue in health professionals. Anxiety, Stress \& Coping. 2013 Nov 1;26(6):595-609.

[21]. Carmeli A, Josman ZE. The relationship among emotional intelligence, task performance, and organizational citizenship behaviors. Human performance. 2006 Oct 1;19(4):403-19.

[22]. Brackett MA, Mayer JD, Warner RM. Emotional intelligence and its relation to everyday behaviour. Personality and Individual differences. $2004 \mathrm{Apr}$ 1;36(6):1387-402.

[23]. Lopes PN, Brackett MA, Nezlek JB, Schütz A, Sellin I, Salovey P. Emotional intelligence and social interaction. Personality and social psychology bulletin. 2004 Aug;30(8):1018-34.

[24]. Pau A, Rowland ML, Naidoo S, AbdulKadir R, Makrynika E, Moraru R, et al. Emotional intelligence and perceived stress in dental undergraduates: a multinational survey. J Dent Educ [Internet]. 2007 Feb;71(2):197-204. Pubmed PMID: 17314380.

[25]. Por J, Barriball L, Fitzpatrick J, Roberts J. Emotional intelligence: its relationship to stress, coping, well-being and professional performance in nursing students. Nurse Educ Today [Internet]. 2011 Nov;31(8):855-60. Pubmed PMID:21292360

[26]. Victoroff KZ, Boyatzis RE. What is the relationship between emotional intelligence and dental student clinical performance? J Dent Educ. 2013 Apr;77(4):416-26.Pubmed PMID: 23576587.

[27]. Polychronopoulou A, Divaris K. A longitudinal study of Greek dental students' perceived sources of stress. J Dent Educ. 2010 May;74(5):524-30. Pubmed PMID: 20442430. 